\title{
Análise da eficiência sócio financeira de cooperativas de crédito no Brasil
}

\author{
Analysis of the socio-financial efficiency of credit unions in Brazil
}

\begin{abstract}
Resumo
O objetivo geral do trabalho foi analisar a eficiência sócio financeira do segmento de crédito cooperativo no Brasil. Esse tipo de estudo diz respeito à avaliação tanto de indicadores de desempenho empresarial quanto de variáveis relacionadas à gestão social desse tipo de empreendimento. Para tanto, foram calculados quocientes financeiros originados dos demonstrativos contábeis dos dois maiores sistemas de crédito cooperativo e dos quatro maiores bancos do País no período de 2014 a 2017, além da apuração dos custos dos principais serviços bancários e das taxas de juros das mais relevantes operações de crédito para as mesmas instituições. Os principais resultados apontam para o desempenho financeiro superior das cooperativas de crédito em relação aos maiores bancos do País. Concomitantemente, aquelas instituições apresentaram, também, satisfatória performance social a partir da constatação de que seus serviços bancários e de crédito tiveram custo inferior aos das demais organizações estudadas.
\end{abstract}

Palavras-chave: Cooperativas de crédito, eficiência sócio financeira, sistema financeiro nacional.

\begin{abstract}
The overall objective of the study was to analyze the social and financial efficiency of the credit unions in Brazil. This type of study concerns the evaluation of both business performance indicators and variables related to the social management of this type of enterprise. For this purpose, financial quotients were calculated from the financial statements of the two largest credit unions systems and the four largest banks in the period from 2014 to 2017, as well as the calculation of the costs of the main banking services and interest rates of the most important operations for the same institutions. The main results point to the superior financial performance of credit unions in relation to the largest banks. At the same time, these institutions also presented a satisfactory social performance based on the fact that their banking and credit services had a lower cost than the others organizations.
\end{abstract}

Keywords: Credit unions, socio-financial efficiency, national financial system.

Brício dos Santos Reis ${ }^{\mathrm{I}}$ Mateus de Carvalho Reis Neves ${ }^{\mathrm{II}}$

I Universidade Federal de Viçosa. bricio@ufv.br

II Universidade Federal de Viçosa. mateus.neves@ufv.br 


\section{Introdução}

O Cooperativismo tem como principal objetivo a inclusão social e econômica das pessoas e, consequentemente, o crescimento de suas opções como consumidores, empreendedores e cidadãos (Frantz, 2001; Frantz, 2003; Rios \& Carvalho, 2007). A ênfase do modelo cooperativista está na conjugação de elementos de natureza empresarial e coletiva no contexto de uma instituição voltada a atender interesses de integração econômica sem, concomitantemente, perder a preocupação com componentes essenciais de caráter solidário, como a gestão democrática, a educação e a relação com a comunidade (Bialoskorski Neto, 2012; Royer, 2014a; Royer, 2014b).

Nesse sentido, as oportunidades advindas desse tipo de empreendimento são inúmeras. Do mesmo modo, o risco que seus integrantes assumem ao se tornarem proprietários de organizações com esse nível de complexidade também é considerável, sobretudo no que diz respeito à necessidade constante de sua participação nas diversas instâncias decisórias.

Essa participação se faz mais necessária à medida que o empreendimento consegue se desenvolver e estabelecer relações mais dinâmicas com o mercado. Todos são solidários perante as obrigações assumidas pela cooperativa e, como tal, podem ser beneficiados pelo seu resultado positivo ou podem ser obrigados a arcar com suas perdas. Assim, espera-se que os cooperados, ao menos, monitorem os caminhos seguidos pela instituição e se comprometam a assumir responsabilidades administrativas adequadas ao seu nível de conhecimento.

Nesse contexto, um dos ramos do cooperativismo merece especial destaque quanto à complexidade de suas relações comerciais: o de crédito. De acordo com a Resolução 4434/2015, do Conselho Monetário Nacional (CMN), as chamadas cooperativas financeiras são classificadas, atualmente, pelos tipos de operações que realizam, e não mais pelas características de seu quadro social. Assim, qualquer grupo de indivíduos pode se organizar e constituir uma Instituição Financeira (IF) que terá muitos atributos semelhantes aos de um banco, mas que será gerida de forma democrática.

Nesse cenário em que é necessário primar pela gestão social de um empreendimento e, ao mesmo tempo, garantir sua competitividade frente a um mercado extremamente concentrado e dominado por grandes conglomerados públicos e privados, torna-se crucial o desenvolvimento de indicadores de desempenho que monitorem essas duas frentes. Em outras palavras, é preciso identificar com propriedade o conceito de eficiência nesse tipo de instituição.

Para tanto, o presente estudo analisou o que define como Eficiência Sócio Financeira, um conceito apropriado às organizações cooperativas que enseja tanto valores que retratam desempenho econômico quanto sua performance no que diz respeito aos objetivos de caráter social, como inclusão bancária, incentivo à poupança e ao crédito, entre outros característicos do ramo financeiro.

Assim, conforme definido por Reis e Fontes (2017), a eficiência sócio financeira está vinculada à capacidade que as cooperativas de crédito apresentam de garantir níveis adequados de liquidez e rentabilidade em seu negócio simultaneamente ao oferecimento de serviços bancários e operações de crédito em condições mais satisfatórias que seus concorrentes no mercado.

Em outras palavras, essas instituições podem ser consideradas eficientes quando permitem que seus associados tenham acesso ao mercado bancário de forma mais vantajosa do que teriam utilizando os serviços oferecidos pelos concorrentes (eficiência social) e, ao mesmo tempo, quando são sustentáveis do ponto de vista econômico (eficiência financeira).

Esse tipo de estudo se faz relevante à medida que o segmento de crédito cooperativo no Brasil vem crescendo significativamente nos últimos anos. De acordo com a Tabela 1, a participação das cooperativas no Sistema Financeiro Nacional - considerando variáveis como Patrimônio Líquido, Ativos, Depósitos e Operações de Crédito - só aumentou entre 2013 e 2017. 
Os dados do Banco Central do Brasil (BCB) (2018b) revelam, ainda, que o número de pessoas associadas às cooperativas de crédito passou de 4,2 milhões em dezembro de 2008 para 9,6 milhões em dezembro de 2017. 0 aumento, segundo o referido relatório, foi obtido mesmo com a redução do número de cooperativas singulares no período, o que pode ser explicado pelo crescimento da escala de atuação das unidades ativas e, consequentemente, de seu maior poder de competição frente à concentração do sistema financeiro brasileiro.

Tabela 1 - Participação das cooperativas de crédito no Patrimônio Líquido, Ativos, Depósitos e Operações de Crédito no segmento financeiro nacional, no período de 2013 a 2017.

\begin{tabular}{ccccccc}
\hline & & $\mathbf{2 0 1 3}$ & $\mathbf{2 0 1 4}$ & $\mathbf{2 0 1 5}$ & $\mathbf{2 0 1 6}$ & $\mathbf{2 0 1 7}$ \\
\hline \multirow{2}{*}{ Patrimônio Líquido } & $\mathrm{R} \$$ bilhões & 19,8 & 23,5 & 28,8 & 33,1 & 38,2 \\
& $\%$ & $2,57 \%$ & $2,93 \%$ & $3,50 \%$ & $3,87 \%$ & $4,24 \%$ \\
\hline \multirow{2}{*}{ Ativos } & $\mathrm{R} \$$ bilhões & 92,2 & 110,6 & 130,5 & 154,2 & 178,5 \\
& $\%$ & $1,41 \%$ & $1,49 \%$ & $1,58 \%$ & $1,87 \%$ & $2,15 \%$ \\
\hline \multirow{2}{*}{ Depósitos } & $\mathrm{R} \$$ bilhões & 50,6 & 61,4 & 74,2 & 91,0 & 105,6 \\
& $\%$ & $2,69 \%$ & $3,11 \%$ & $3,55 \%$ & $4,26 \%$ & $4,50 \%$ \\
\hline \multirow{2}{*}{ Operações de Crédito } & $\mathrm{R} \$$ bilhões & 57,6 & 67,7 & 76,0 & 83,6 & 95,9 \\
& $\%$ & $1,95 \%$ & $2,04 \%$ & $2,09 \%$ & $2,42 \%$ & $2,81 \%$ \\
\hline
\end{tabular}

Fonte: Banco Central do Brasil (2018b).

0 dado mais relevante, entretanto, diz respeito à participação das cooperativas no mercado de crédito nacional. Em 2005, essas instituições respondiam por algo em torno de 5,2\% dos empréstimos/financiamentos tomados por pessoas físicas e menos de $1 \%$ daqueles destinados às pessoas jurídicas. Já em 2017, esses valores passaram para 6,5\% e 8\%, respectivamente (BCB, 2018b). Essas estatísticas revelam o aumento da relevância do segmento de crédito cooperativo, sobretudo, para o financiamento da atividade produtiva no País.

Nesse contexto, o objetivo central do presente artigo é analisar o desempenho econômico e social de cooperativas de crédito face aos seus principais concorrentes no Sistema Financeiro Nacional (SFN). A ideia é verificar se mesmo diante de um mercado concentrado e desafiador, aquelas instituições conseguem obter bons indicadores de desempenho tanto do ponto de vista empresarial quanto no que diz respeito ao seu papel social, característica intrínseca às organizações constituídas sob a forma cooperativa.

Para tanto, o texto está dividido em quatro seções, além dessa introdução. A segunda aborda os principais conceitos teóricos relacionados ao tema central da pesquisa. Na sequência, descreve-se o método utilizado para alcançar os objetivos propostos. Em seguida, são destacados e discutidos os principais resultados. Por fim, considerações são tecidas a respeito das conclusões plausíveis e sugestões para continuidade da pesquisa são apresentadas.

\section{Abordagem do Tema}

Oliveira Junior (1996) destaca que as cooperativas são sociedades de pessoas e, portanto, têm no processo de acumulação de capital próprio um meio, e não um fim em si só. 0 incremento da capacidade de investimento é, apenas, uma etapa para o alcance do objetivo principal, que se resume na satisfação dos interesses dos associados. Contudo, esse tipo de recurso é essencial para o desenvolvimento e a sustentabilidade dos empreendimentos cooperativos.

Franke (1996) reforça essa interpretação à media que relata os percalços do modelo Raiffeisen de crédito cooperativo na Alemanha da segunda metade do século XIX. As instituições que deram 
origem a esse movimento entendiam que poderiam sobreviver sem a necessidade de subscrição de capital. Entretanto, com o incremento de suas atividades, passaram a enfrentar sérias dificuldades para garantir suas operações e, em pouco tempo, assumiram a necessidade de integralização de quotas por parte de seus associados e de capitalização dos resultados para fortalecimento de sua estrutura financeira.

Assim, faz-se crucial enfatizar a necessidade do processo de acumulação de capital para a sobrevivência dos empreendimentos cooperativos. Para cooperativas de crédito, especificamente, a maximização dos benefícios aos cooperados - materializados em operações de crédito e serviços bancários com preços mais acessíveis - de forma concomitante à garantia de condições de rentabilidade e solvência do negócio, conforme enfatizado por Reis e Fontes (2017), tem no incremento do capital próprio condição sine qua non para seu alcance.

Entretanto, como nesse tipo de instituição cada pessoa tem direito a um voto e a distribuição das sobras é realizada de acordo com a movimentação efetiva, o que se verifica é o desestímulo à inversão de recursos que extrapolam o mínimo necessário para assunção do papel de cooperado. Assim, cabe à própria entidade a tarefa de se capitalizar, gerando resultados suficientes para arcar com suas necessidades de investimento.

O dilema, contudo, está na calibragem dos resultados alcançados. Em outras palavras, na definição de valores ótimos para suas sobras, que são geradas, basicamente, pelas operações realizadas com seus associados. São esses agentes que se configuram como fornecedores e clientes das cooperativas financeiras, uma vez que tanto suas operações de crédito quanto a maioria de seus serviços bancários devem ser realizados, por imposição legal, apenas com cooperados.

Medidas de redução de custos, como a definição de menores taxas de remuneração dos depósitos a prazo, e de incremento de receitas, como a determinação de juros mais elevados nas operações de crédito, terão impacto direto no quadro social. Esses são exemplos claros de ações que podem garantir maior nível de eficiência financeira ao negócio cooperativo e, ao mesmo tempo, prejudicar seu público-alvo e distorcer sua função social.

Por isso, faz-se extremamente necessário acompanhar os indicadores de desempenho financeiro das cooperativas de crédito à luz de sua performance social. Não se pode dissociar esses dois tipos de análise, sob pena de realizar avaliação incompleta e tendenciosa. A eficiência das cooperativas só pode ser determinada quando sua dupla natureza, social e econômica, é contemplada pelas técnicas aplicadas (Carvalho, Diaz, Bialoskorski \& Kalatzis, 2015).

\section{Método}

A partir dessas considerações, cabe destacar que a técnica de análise de balanços, conforme descrito por Assaf Neto e Lima (2017), pode ser utilizada para avaliação do desempenho econômicofinanceiro de uma instituição, com destaque para os indicadores de liquidez, estrutura patrimonial e rentabilidade. Ainda segundo os referidos autores, mesmo que existam modelos de análise mais sofisticados, o cálculo de quocientes originados das demonstrações contábeis se constitui no procedimento mais comum para verificação da eficiência.

Assaf Neto e Lima (2017) destacam, também, que a comparação dos indicadores selecionados entre empresas concorrentes e a determinação dos mesmos para um período de tempo considerável (normalmente, entre três e cinco anos) garantem melhor qualidade aos resultados e, consequentemente, maior abrangência às conclusões. Dentre os principais quocientes citados pelos referidos autores, destacam-se os elencados na Tabela 2. 
Tabela 2 - Indicadores Tradicionais de Análise de Balanços

\begin{tabular}{|c|c|}
\hline INDICADOR & FóRMULA \\
\hline Liquidez Corrente & Ativo Circulante / Passivo Circulante \\
\hline Liquidez Imediata & Disponível / Passivo Circulante \\
\hline Endividamento & Passivo / Ativo \\
\hline Retorno sobre o Ativo & Resultado Operacional / Ativo \\
\hline Retorno sobre o Capital Próprio & Resultado Líquido / Patrimônio Líquido \\
\hline
\end{tabular}

Fonte: Assaf Neto e Lima (2017).

Já em relação aos indicadores específicos para instituições financeiras cooperativas, muitos estudos procuraram trabalhar com o sistema PEARLS, acrônimo para um grupo de quocientes financeiros definidos a partir das seguintes áreas: Protection (proteção), Effective Finantial Structure (estrutura financeira efetiva), Assets Quality (qualidade dos ativos), Rates of Return and Costs (taxas de retorno e custos), Liquidity (liquidez) e Signs of Growth (sinais de crescimento). Esse método de análise foi proposto e é amplamente utilizado pelo Conselho Mundial de Cooperativas de Crédito (World Council of Credit Unions - WOCCU).

Nesse contexto, a pesquisa de Bressan, Braga, Bressan \& Resende Filho (2011a) teve como objetivo analisar a capacidade de predição de insolvência dos diversos indicadores desse sistema para a realidade das cooperativas de crédito brasileiras. Para tanto, os autores estimaram um modelo LOGIT para uma amostra de mais de quinhentas singulares filiadas ao SICOOB - Sistema de Cooperativas de Crédito do Brasil.

Bressan, Braga, Bressan \& Resende Filho (2011b) aplicaram a mesma sistemática para cooperativas de crédito do Estado de Minas Gerais e Bressan, Bressan, Oliveira \& Braga (2014) o fizeram tendo como público-alvo as cooperativas centrais do SICOOB. Esses trabalhos chegaram a conclusões semelhantes sobre os quocientes financeiros mais importantes para análise do desempenho dessas sociedades de pessoas, com diferenças, apenas, relacionadas à inclusão e/ou exclusão de um ou dois indicadores entre os mais significativos.

Da mesma forma, Gonçalves (2005), Ferreira, Gonçalves \& Braga (2007) e Carvalho et al. (2015) também analisaram desempenho financeiro de cooperativas de crédito em diferentes regiões do Brasil. Esses autores utilizaram diversos indicadores para retratar a situação econômica e a performance dessas instituições ao longo de períodos variados.

Com base nesses estudos, foram selecionados os quocientes financeiros descritos na Tabela 3. Os percentuais de depósitos à vista e a prazo em relação ao total de obrigações da entidade despontaram no estudo de Carvalho et al. (2015) como bons preditores de insolvência, sendo confirmadas suas relações negativas com esse tipo de problema. No mesmo estudo, a relação entre operações de crédito e ativo total também se apresentou como negativamente relacionada a problemas de liquidez. 
REIS. B. S.; NEVES. M. C. R.| 208

Tabela 3 - Indicadores Específicos de Análise de Balanços em Cooperativas de Crédito

\begin{tabular}{|c|c|}
\hline INDICADOR & FóRMULA \\
\hline Captação por Depósitos à Vista & Depósitos à Vista / Passivo \\
\hline Captação por Depósitos a Prazo & Depósitos a Prazo / Passivo \\
\hline Aplicações em Operações de Crédito & Operações de Crédito / Ativo \\
\hline Capital Social & Capital Social / Ativo \\
\hline Capital Institucional & Capital Institucional / Ativo \\
\hline Despesas Operacionais & Despesas Operacionais / Ativo \\
\hline
\end{tabular}

Fonte: Gonçalves (2005), Ferreira et al. (2007), Bressan et al. (2011a), Bressan et al. (2011b), Bressan et al. (2014) e Carvalho et al. (2015).

Já nas pesquisas de Ferreira et al. (2007), Bressan et al. (2011a), Bressan et. al. (2011b) e Bressan et. al. (2014) os quocientes de Capital Social e Capital Institucional se destacaram como importantes indicadores de problemas financeiros. O Capital Social é o montante de recursos investido diretamente pelos associados, seja por integralização inicial ou por aportes posteriores de recursos, como a incorporação de sobras. O Capital Institucional, por sua vez, diz respeito ao restante do capital próprio da organização, composto por Reserva Legal (Fundo de Reserva), Sobras à Disposição da Assembleia e outros componentes do Patrimônio Líquido. Quanto maior sua participação no montante de recursos captados, maior tende a ser a segurança da cooperativa e sua capacidade de realização de investimentos. Esses mesmos autores também identificaram que quanto menor o volume de despesas operacionais em relação ao ativo, maior a chance das cooperativas financeiras terem sucesso em suas atividades.

Tais indicadores, portanto, fizeram parte do contexto de análise da presente pesquisa. Seus valores foram obtidos por meio das demonstrações contábeis dos maiores bancos, no que diz respeito ao valor total de seus ativos, do Sistema Financeiro Nacional (Banco do Brasil, Caixa Econômica Federal, Itaú e Bradesco), e dos dois principais sistemas de crédito cooperativo do País (SICOOB e SICREDI), todas divulgadas em seus respectivos sites e, portanto, tornadas públicas. 0 período de análise compreendeu os anos de 2014 a 2017, uma vez que os referidos sites não dispunham de informações mais antigas para que se pudesse estender o período de análise. A Caixa Econômica Federal, apesar de ser uma instituição financeira puramente pública, foi selecionada em virtude de sua relevância em termos de serviços bancários oferecidos ao público em geral e, sobretudo, em virtude de sua forte inserção no mercado de crédito imobiliário.

Cabe destacar, em relação aos sistemas de crédito cooperativo, que foram analisadas as demonstrações contábeis combinadas, ou seja, aquelas que envolvem, além das cooperativas Singulares e Centrais, as demais entidades que compõem o conglomerado financeiro, como os Bancos Cooperativos e as Distribuidoras de Títulos e Valores Mobiliários, por exemplo. Assim, os indicadores avaliados refletem o desempenho de todo o segmento, dando maior abrangência à análise e permitindo que as conclusões possam ser estendidas a uma maior gama de atividades desenvolvidas pelas cooperativas e suas organizações de apoio.

Para que as diversas demonstrações pudessem ser comparadas, as mesmas foram padronizadas, o que, como bem definido por Silva (2017), consiste em etapa essencial para a realização de uma boa análise econômico-financeira, especialmente quando o objetivo envolve a comparação com outras empresas do setor. Como as instituições financeiras organizam sua contabilidade nos moldes do Plano de Contas do Sistema Financeiro (COSIF), essa tarefa se tornou bem mais simples à medida que os relatórios já se encontram em formato padrão do setor, tendo sido necessário, apenas, pequenos ajustes para fins comparativos. 
O passo seguinte envolveu a atualização monetária dos valores contábeis, ou, em outras palavras, o deflacionamento desses valores, já que foram utilizados dados de períodos diferentes. Como enfatizaram Takamtsu e Lamounier (2006), é essencial que os dados em moeda corrente, disponibilizados nos relatórios financeiros das empresas, sejam atualizados para um mesmo período, normalmente o último, para fins de comparação das informações.

Os mesmos autores citam os índices da Fundação Getúlio Vargas (FGV), entre outros, como bons instrumentos de atualização monetária. Nesse sentido, o presente trabalho utilizou o Índice Geral de Preços de Mercado (IGP-M) como deflator para atualização dos dados contábeis das diversas instituições financeiras que fizeram parte do estudo.

A partir da padronização dos relatórios contábeis e da atualização dos seus valores, foram calculados os indicadores descritos nas Tabelas 2 e 3, tanto para os dados consolidados do SICOOB e do SICREDI, quanto para os principais bancos públicos e privados que concentram a maior parcela do mercado financeiro no Brasil. Os resultados encontrados, então, foram comparados no intuito de verificar se as cooperativas de crédito apresentam padrão de eficiência financeira semelhante ao dos seus principais concorrentes.

Entretanto, como bem definido por Oliveira Júnior (1996), a ótica analítica voltada à avaliação da rentabilidade e produtividade do capital é insuficiente para definir a eficiência de uma cooperativa, devendo sua capacidade de prestar serviços aos cooperados também ser objeto de análise. Peixe e Protil (2007) enfatizaram essa necessidade ao analisarem cooperativas agroindustriais do Paraná, destacando que apenas a utilização de indicadores financeiros não é suficiente para avaliar esse tipo de organização.

Sendo assim, a presente pesquisa utilizou o custo dos diversos serviços bancários ofertados pelas cooperativas e seus principais concorrentes como proxy para definição da eficiência social das primeiras. A ideia consistiu em averiguar se o segmento de crédito cooperativo tem contribuído para a inclusão financeira de seu quadro social com o oferecimento de condições vantajosas em relação aos bancos que, hoje, detêm a maior parcela do mercado. Os serviços que tiveram seus valores comparados na presente pesquisa encontram-se descritos na Tabela 4.

Tabela 4 - Serviços Bancários para Comparação de Tarifas entre Cooperativas de Crédito e Bancos Públicos e Privados

\begin{tabular}{|c|c|}
\hline Confecção de cadastro inicial & Transferência por DOC/TED pessoal \\
\hline Cartão de Débito - fornecimento de $2^{\mathrm{a}}$ via & Transferência por DOC/TED agendada \\
\hline Fornecimento de folhas de cheque & Transferência por DOC/TED internet \\
\hline $\begin{array}{c}\text { Exclusão do Cadastro de Emitentes de Cheque sem } \\
\text { Fundos (CCF) }\end{array}$ & $\begin{array}{c}\text { Transferência entre contas da própria } \\
\text { instituição }\end{array}$ \\
\hline Cheque Administrativo & $\begin{array}{l}\text { Cartão de Crédito - fornecimento de } \\
\text { 2a via }\end{array}$ \\
\hline Saque pessoal - conta corrente e poupança & $\begin{array}{l}\text { Saques de Cartão de Crédito em } \\
\text { espécie }\end{array}$ \\
\hline Saque no terminal - conta corrente e poupança & $\begin{array}{l}\text { Pagamento por Cartão de Crédito em } \\
\text { espécie }\end{array}$ \\
\hline $\begin{array}{l}\text { Fornecimento de extrato de conta corrente e } \\
\text { poupança }\end{array}$ & Avaliação emergencial de crédito \\
\hline
\end{tabular}

Fonte: Elaborado pelo autor a partir de dados divulgados pelo Banco Central do Brasil.

Já em relação às operações de crédito, as mais importantes, de acordo com o Panorama do Sistema Nacional de Crédito Cooperativo (BCB, 2018b), encontram-se destacadas na Tabela 5. Os custos desses empréstimos/financiamentos foram analisados no contexto das pessoas físicas e 
jurídicas a fim de determinar a forma de atuação das cooperativas e dos bancos públicos e privados no mercado financeiro.

Tabela 5 - Tipos de Operações de Crédito para Comparação de Custos entre Cooperativas de Crédito e Bancos Públicos e Privados

\begin{tabular}{|c|c|}
\hline Pessoas Físicas & Pessoas Jurídicas \\
\hline Empréstimo Consignado & Capital de Giro \\
\hline Empréstimo sem Consignação & Capital de Giro Rotativo \\
\hline Veículos & Investimento \\
\hline & Operações com Recebíveis \\
\hline
\end{tabular}

Fonte: Elaborado pelo autor a partir de dados divulgados pelo Banco Central do Brasil.

Para pessoas físicas, o empréstimo consignado envolve o desconto das prestações em folha de pagamento. Já os sem consignação, por não possuírem essa alternativa, se configuram como mais arriscados para as instituições financeiras. 0 financiamento para compra de veículos, por sua vez, também é considerado como de baixo risco, pois, têm como garantia real o próprio bem que está sendo financiado.

Para pessoas jurídicas, a disponibilização de recursos para capital de giro pode ser imediata ou realizada de forma rotativa, isto é, previamente acordada para que, quando houver necessidade por parte da empresa, o montante possa ser sacado. Já os financiamentos para investimento (longo prazo) e as operações com recebíveis implicam em menores níveis de risco para as instituições financeiras, uma vez que são garantidos pelos bens adquiridos, no caso do primeiro, e pelos próprios títulos de crédito que são repassados aos credores, no segundo.

Por fim, e visando ampliar a robustez das análises financeiras, foi aplicado o teste estatístico de Tukey (TUKEY, 1953; JACCARD et al., 1984). Tal teste é adequado para a comparação de múltiplas médias, concomitantemente, a fim de se verificar a existência de diferenças estatisticamente significativas entre elas.

\section{Resultados e Discussão}

Em relação à eficiência econômico-financeira dos sistemas de crédito cooperativo, a primeira vertente de análise considerada foi liquidez, composta por quocientes que relacionam a disponibilidade de bens e direitos com as dívidas das instituições relacionadas na pesquisa (Tabela 6). Valores mais elevados desses indicadores representam maior capacidade de liquidação das obrigações assumidas e, consequentemente, menor risco de insolvência. 
Tabela 6 - Quocientes de Solvência, 2014 a 2017.

\begin{tabular}{|c|c|c|c|c|c|c|}
\hline Liquidez Imediata & 2014 & 2015 & 2016 & 2017 & Média & Tukey* \\
\hline SICOOB & 0,0833 & 0,1338 & 0,1768 & 0,2176 & 0,1529 & $\mathrm{~d}$ \\
\hline SICREDI & 0,5814 & 0,6057 & 0,6325 & 0,5028 & 0,5806 & $\mathrm{a}$ \\
\hline $\mathrm{BB}$ & 0,3385 & 0,4063 & 0,4157 & 0,3820 & 0,3856 & $\mathrm{~b}$ \\
\hline CEF & 0,2155 & 0,2307 & 0,2502 & 0,2290 & 0,2313 & $\mathrm{~cd}$ \\
\hline ITAÚ & 0,3791 & 0,4228 & 0,4040 & 0,3638 & 0,3924 & $\mathrm{~b}$ \\
\hline BRADESCO & 0,3389 & 0,2342 & 0,2408 & 0,2041 & 0,2545 & c \\
\hline Liquidez Corrente & 2014 & 2015 & 2016 & 2017 & Média & \\
\hline SICOOB & 0,6655 & 0,7095 & 0,7328 & 0,8068 & 0,7286 & $\mathrm{~d}$ \\
\hline SICREDI & 1,7312 & 1,9824 & 2,1795 & 2,0250 & 1,9795 & $\mathrm{a}$ \\
\hline $\mathrm{BB}$ & 0,9073 & 0,8481 & 0,8007 & 0,7644 & 0,8301 & $\mathrm{~cd}$ \\
\hline CAIXA & 0,8274 & 0,8298 & 0,8979 & 0,8508 & 0,8515 & $\mathrm{~cd}$ \\
\hline ITAÚ & 1,3208 & 1,3422 & 1,3379 & 1,3728 & 1,3434 & $\mathrm{~b}$ \\
\hline BRADESCO & 0,9229 & 1,0014 & 0,9427 & 0,9578 & 0,9607 & $\mathrm{C}$ \\
\hline
\end{tabular}

* Letras iguais indicam que, no nível de 5\% de significância, não há diferença entre as médias.

Fonte: Dados da pesquisa.

De acordo com os dados, pode-se verificar a disparidade entre os dois sistemas de crédito cooperativo. Enquanto as instituições que compõem o SICOOB apresentaram os menores valores para os quocientes de Liquidez Imediata e Liquidez Corrente durante todo o período de análise, as organizações do SICREDI são as que possuem o maior nível de recursos à disposição para contrapor seu passivo, superando, inclusive, tanto os bancos públicos (BB e Caixa) quanto os privados (Itaú e Bradesco).

Esse nível inferior de liquidez do SICOOB, com média equivalente às dos bancos públicos, pode estar associado ao menor volume de endividamento e ao maior contingente de Capital Social das organizações desse sistema (Tabela 7). Aliás, as cooperativas de crédito e suas instituições de apoio apresentaram menor Passivo e maiores Capitais Social e Institucional que os conglomerados financeiros públicos e privados no período de análise.

Tabela 7 - Quocientes de Estrutura de Capitais, 2014 a 2017.

\begin{tabular}{ccccccc}
\hline Endividamento & $\mathbf{2 0 1 4}$ & $\mathbf{2 0 1 5}$ & $\mathbf{2 0 1 6}$ & $\mathbf{2 0 1 7}$ & Média & Tukey* \\
\hline SICOOB & $75,8 \%$ & $76,2 \%$ & $78,3 \%$ & $79,5 \%$ & $77,4 \%$ & $\mathrm{~d}$ \\
\hline SICREDI & $85,0 \%$ & $84,0 \%$ & $83,1 \%$ & $83,1 \%$ & $83,8 \%$ & $\mathrm{c}$ \\
\hline BB & $94,4 \%$ & $94,2 \%$ & $93,8 \%$ & $92,8 \%$ & $93,8 \%$ & $\mathrm{a}$ \\
\hline CAIXA & $94,2 \%$ & $94,8 \%$ & $94,9 \%$ & $94,3 \%$ & $94,6 \%$ & $\mathrm{a}$ \\
\hline ITAÚ & $91,8 \%$ & $91,9 \%$ & $90,9 \%$ & $90,6 \%$ & $91,3 \%$ & $\mathrm{~b}$ \\
\hline BRADESCO & $91,1 \%$ & $91,2 \%$ & $91,4 \%$ & $90,8 \%$ & $91,1 \%$ & $\mathrm{~b}$ \\
\hline Capital Social & $\mathbf{2 0 1 4}$ & $\mathbf{2 0 1 5}$ & $\mathbf{2 0 1 6}$ & $\mathbf{2 0 1 7}$ & Média & \\
\hline SICOOB & $16,2 \%$ & $15,9 \%$ & $14,5 \%$ & $13,4 \%$ & $15,0 \%$ & $\mathrm{a}$ \\
\hline SICREDI & $7,6 \%$ & $7,8 \%$ & $8,6 \%$ & $8,1 \%$ & $8,0 \%$ & $\mathrm{~b}$ \\
\hline BB & $3,8 \%$ & $4,3 \%$ & $4,8 \%$ & $4,9 \%$ & $4,4 \%$ & $\mathrm{~d}$ \\
\hline CAIXA & $2,1 \%$ & $1,8 \%$ & $2,0 \%$ & $2,4 \%$ & $2,1 \%$ & $\mathrm{e}$ \\
\hline ITAÚ & $6,2 \%$ & $6,3 \%$ & $6,8 \%$ & $6,5 \%$ & $6,4 \%$ & $\mathrm{c}$ \\
\hline
\end{tabular}


REIS. B. S.; NEVES. M. C. R.| 212

\begin{tabular}{ccccccc}
\hline BRADESCO & $4,1 \%$ & $4,2 \%$ & $4,3 \%$ & $4,9 \%$ & $4,4 \%$ & $\mathrm{~d}$ \\
\hline $\begin{array}{c}\text { Capital } \\
\text { Institucional }\end{array}$ & $\mathbf{2 0 1 4}$ & $\mathbf{2 0 1 5}$ & $\mathbf{2 0 1 6}$ & $\mathbf{2 0 1 7}$ & Média & \\
\hline SICOOB & $8,1 \%$ & $8,0 \%$ & $7,2 \%$ & $7,1 \%$ & $7,6 \%$ & $\mathrm{a}$ \\
\hline SICREDI & $6,9 \%$ & $7,6 \%$ & $7,8 \%$ & $8,4 \%$ & $7,7 \%$ & $\mathrm{a}$ \\
\hline BB & $3,4 \%$ & $4,2 \%$ & $4,1 \%$ & $4,5 \%$ & $4,1 \%$ & $\mathrm{~b}$ \\
\hline CAIXA & $4,3 \%$ & $4,2 \%$ & $4,2 \%$ & $4,8 \%$ & $4,4 \%$ & $\mathrm{~b}$ \\
\hline ITAÚ & $2,0 \%$ & $2,4 \%$ & $2,0 \%$ & $2,7 \%$ & $2,3 \%$ & $\mathrm{c}$ \\
\hline BRADESCO & $4,9 \%$ & $5,4 \%$ & $4,4 \%$ & $4,3 \%$ & $4,7 \%$ & $\mathrm{~b}$ \\
\hline
\end{tabular}

* Letras iguais indicam que, no nível de 5\% de significância, não há diferença entre as médias. Fonte: Dados da pesquisa.

Essa maior captação de recursos próprios, de certa forma, contraria a lógica de falta de atratividade financeira das quotas-partes das cooperativas para seus associados. Uma vez que as mesmas trabalham com maior proporção de Capital Próprio que as principais instituições financeiras do País, pode-se dizer que, de alguma forma, suas políticas de autofinanciamento têm surtido efeito, a despeito da baixa possibilidade de remuneração (limitada à taxa SELIC) e do alto risco associados a esse tipo de investimento.

De qualquer maneira, esses números permitem concluir que, em termos de garantia dos investimentos, as cooperativas de crédito são mais eficientes que seus principais concorrentes. Como as inversões em ativos devem ser lastreadas por montante compatível de Patrimônio de Referência conforme definido nas Resoluções 4.192 e 4.193, de 01 de março de 2013, e 4.606, de 19 de outubro de 2017 -, a maior representatividade desse tipo de capital nos sistemas de crédito cooperativo garante maior segurança às suas instituições.

Reforçando esse aspecto, os estudos de Bressan et al. (2011a) e Bressan et al. (2011b) identificaram que os quocientes de Capital Social e Capital Institucional são dois dos mais importantes preditores de insolvência em cooperativas de crédito. Segundo os autores, quanto maiores seus valores, menores as chances de insucesso para esses empreendimentos. Assim, considerando a diferença estatística entre as magnitudes desses indicadores para os sistemas cooperativos e as demais instituições financeiras, pode-se dizer que o desempenho daqueles é bem superior nesse quesito.

Essa característica de solidez financeira é fortalecida pelo Índice de Basileia do segmento cooperativista que, de acordo com o BCB (2018b), manteve-se em torno de $30 \%$ no último ano, contra um valor de $18 \%$ para as instituições bancárias. Esse indicador mede o grau de alavancagem financeira das organizações pela razão entre seu Patrimônio de Referência e os diversos tipos de investimento realizados, ponderados pelo risco associado a cada um deles. Em outras palavras, quanto maior seu valor, maior a segurança do empreendimento e, consequentemente, de seus clientes/proprietários.

Em relação ao Passivo, o estudo de Carvalho et al. (2015) apontou que os índices de Captação por Depósitos à Vista e a Prazo se sobressaíram como bons elementos de avaliação de desempenho para cooperativas financeiras. Os autores identificaram que suas magnitudes são positivamente relacionadas às chances de sucesso desses empreendimentos. Conforme pode ser observado, tanto o SICOOB quanto o SICREDI, mais uma vez, se destacaram no contexto das instituições analisadas (Tabela 8). 
Tabela 8 - Quocientes de Captação de Depósitos, 2014 a 2017.

\begin{tabular}{ccccccc}
\hline Depósitos à Vista & $\mathbf{2 0 1 4}$ & $\mathbf{2 0 1 5}$ & $\mathbf{2 0 1 6}$ & $\mathbf{2 0 1 7}$ & Média & Tukey* \\
\hline SICOOB & $15,7 \%$ & $14,4 \%$ & $13,6 \%$ & $14,4 \%$ & $14,5 \%$ & $\mathrm{a}$ \\
\hline SICREDI & $11,0 \%$ & $10,4 \%$ & $10,6 \%$ & $11,2 \%$ & $10,8 \%$ & $\mathrm{~b}$ \\
\hline BB & $5,5 \%$ & $5,0 \%$ & $5,3 \%$ & $5,5 \%$ & $5,3 \%$ & $\mathrm{c}$ \\
\hline CAIXA & $2,7 \%$ & $2,4 \%$ & $2,7 \%$ & $2,7 \%$ & $2,6 \%$ & $\mathrm{~d}$ \\
\hline ITAÚ & $4,4 \%$ & $4,9 \%$ & $4,7 \%$ & $5,1 \%$ & $4,8 \%$ & $\mathrm{c}$ \\
\hline BRADESCO & $3,9 \%$ & $2,6 \%$ & $3,1 \%$ & $3,1 \%$ & $3,2 \%$ & $\mathrm{~d}$ \\
\hline Depósitos a Prazo & $\mathbf{2 0 1 4}$ & $\mathbf{2 0 1 5}$ & $\mathbf{2 0 1 6}$ & $\mathbf{2 0 1 7}$ & Média & \\
\hline SICOOB & $66,4 \%$ & $66,7 \%$ & $67,3 \%$ & $63,1 \%$ & $65,9 \%$ & $\mathrm{a}$ \\
\hline SICREDI & $63,3 \%$ & $63,5 \%$ & $67,7 \%$ & $67,3 \%$ & $65,4 \%$ & $\mathrm{a}$ \\
\hline BB & $29,0 \%$ & $30,2 \%$ & $28,7 \%$ & $29,9 \%$ & $29,4 \%$ & $\mathrm{c}$ \\
\hline CAIXA & $39,1 \%$ & $37,5 \%$ & $40,3 \%$ & $39,8 \%$ & $39,2 \%$ & $\mathrm{~b}$ \\
\hline ITAÚ & $22,2 \%$ & $18,5 \%$ & $20,7 \%$ & $24,5 \%$ & $21,5 \%$ & $\mathrm{~d}$ \\
\hline BRADESCO & $21,2 \%$ & $18,5 \%$ & $18,6 \%$ & $21,0 \%$ & $19,8 \%$ & $\mathrm{~d}$ \\
\hline
\end{tabular}

* Letras iguais indicam que, no nível de 5\% de significância, não há diferença entre as médias. Fonte: Dados da pesquisa.

Enquanto a média do período é de pouco mais de $5 \%$ de Depósitos à Vista e de $39 \%$ de Depósitos a Prazo, em relação ao total do passivo, para os bancos que mais captam esse tipo de recurso, os sistemas de crédito cooperativo apresentam valores da ordem de 14,5\% e 65,9\% (SICOOB) e $10,8 \%$ e $65,4 \%$ (SICREDI), respectivamente.

Esses cálculos demonstram a importância das cooperativas no tocante à inclusão financeira no Brasil. Enquanto as demais instituições concentram sua captação de recursos na forma de outros passivos, como a troca de recursos entre as mesmas, as cooperativas de crédito têm procurado abrir as portas do mercado bancário ao seu público-alvo, oferecendo alternativas de movimentação e aplicação de recursos pouco atrativas para seus principais competidores.

Outro indicador que demonstra essa preocupação social dos sistemas de crédito cooperativo é o percentual das Operações de Crédito em relação aos investimentos totais (Figura 1). 0 único banco que, estatisticamente, se equipara às cooperativas de crédito nesse quesito é a Caixa Econômica Federal que, por ser a principal operadora do Sistema Financeiro de Habitação (SFH), tem expressiva atuação no mercado de crédito imobiliário no Brasil. Como bem ressaltaram Bressan et al. (2011a) e Carvalho et al. (2015), esse indicador é um bom termômetro de sucesso para as cooperativas financeiras, tendo relação negativa com a possibilidade de fechamento das mesmas.

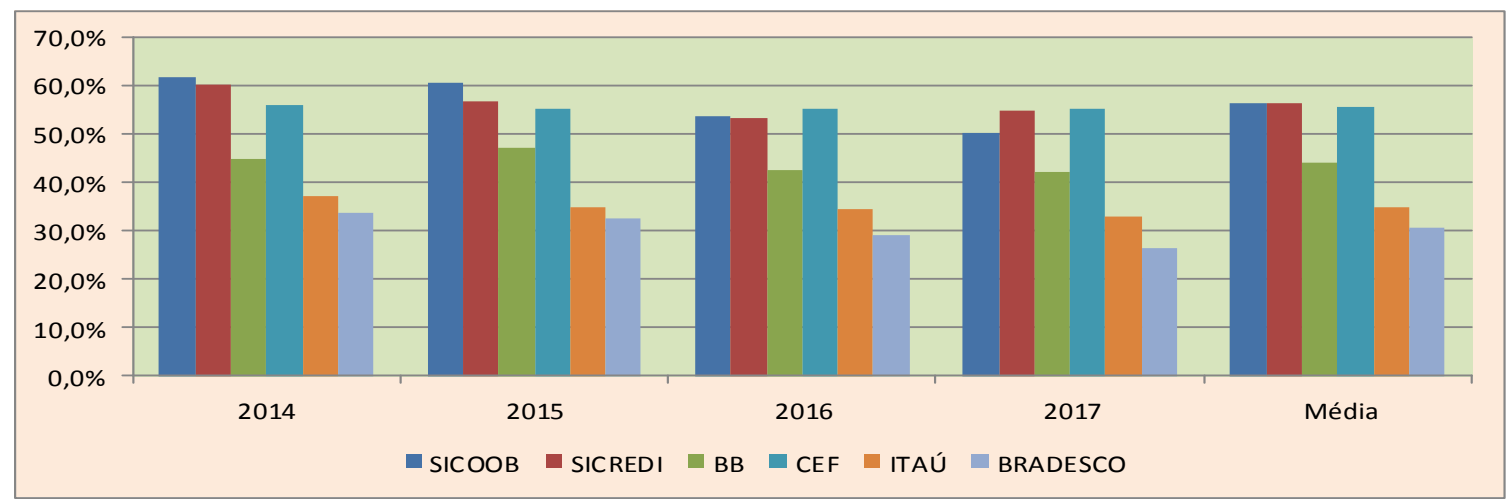

Figura 1 - Quociente de Operações de Crédito, 2014 a 2017.

Fonte: Dados da pesquisa. 
No intuito de verificar se as políticas de captação e aplicação de recursos das cooperativas têm sido eficientes do ponto de vista financeiro, foram calculados os indicadores de rentabilidade (Tabela 9). Como o cálculo desses quocientes envolve valores médios para o Ativo, no caso da Rentabilidade dos Investimentos (ROA), e para o Patrimônio Líquido, no caso da Rentabilidade do Capital Próprio (ROE), não foi possível determinar seus valores para o primeiro ano da série.

Tabela 9 - Quocientes de Rentabilidade, 2014 a 2017.

\begin{tabular}{ccccccc}
\hline ROA & $\mathbf{2 0 1 4}$ & $\mathbf{2 0 1 5}$ & $\mathbf{2 0 1 6}$ & $\mathbf{2 0 1 7}$ & Média & Tukey* \\
\hline SICOOB & - & $4,2 \%$ & $3,8 \%$ & $3,7 \%$ & $3,9 \%$ & $\mathrm{a}$ \\
\hline SICREDI & - & $3,4 \%$ & $3,8 \%$ & $3,8 \%$ & $3,7 \%$ & $\mathrm{a}$ \\
\hline BB & - & $0,4 \%$ & $1,0 \%$ & $1,3 \%$ & $0,9 \%$ & $\mathrm{~b}$ \\
\hline CAIXA & - & $0,1 \%$ & $0,3 \%$ & $1,2 \%$ & $0,5 \%$ & $\mathrm{~b}$ \\
\hline ITAÚ & - & $1,1 \%$ & $2,5 \%$ & $2,3 \%$ & $1,9 \%$ & b \\
\hline BRADESCO & - & $0,9 \%$ & $2,5 \%$ & $1,7 \%$ & $1,7 \%$ & b \\
\hline ROE & $\mathbf{2 0 1 4}$ & $\mathbf{2 0 1 5}$ & $\mathbf{2 0 1 6}$ & $\mathbf{2 0 1 7}$ & Média & \\
\hline SICOOB & - & $16,1 \%$ & $15,2 \%$ & $15,9 \%$ & $15,8 \%$ & $\mathrm{a}$ \\
\hline SICREDI & - & $18,6 \%$ & $20,1 \%$ & $20,0 \%$ & $19,6 \%$ & $\mathrm{a}$ \\
\hline BB & - & $16,9 \%$ & $9,2 \%$ & $11,9 \%$ & $12,7 \%$ & $\mathrm{a}$ \\
\hline CAIXA & - & $10,9 \%$ & $6,3 \%$ & $18,6 \%$ & $11,9 \%$ & $\mathrm{a}$ \\
\hline ITAÚ & - & $22,0 \%$ & $18,8 \%$ & $19,8 \%$ & $20,2 \%$ & $\mathrm{a}$ \\
\hline BRADESCO & - & $19,2 \%$ & $15,4 \%$ & $13,9 \%$ & $16,2 \%$ & $\mathrm{a}$ \\
\hline
\end{tabular}

* Letras iguais indicam que, no nível de 5\% de significância, não há diferença entre as médias.

Fonte: Dados da pesquisa.

Como se pode notar, tanto o SICOOB quanto o SICREDI se destacam no que diz respeito ao retorno alcançado pelo negócio, refletido em termos do ROA. Assaf Neto e Lima (2017) argumentam que esse indicador reflete o desempenho das atividades principais do empreendimento ao comparar o resultado obtido com as operações principais, chamadas de operacionais, e o total de recursos empregado para sua obtenção (Ativo). Enquanto os sistemas de crédito cooperativo apresentaram médias próximas a $4 \%$ ao ano, os bancos públicos não alcançaram $1 \%$ de retorno anual. Já as instituições privadas chegaram a pouco menos de $2 \%$ como média de rentabilidade no período. Todos os valores são estatisticamente diferentes de acordo com os testes realizados.

No que diz respeito ao retorno dos proprietários, as organizações cooperativas e seus empreendimentos apresentaram valores médios estatisticamente iguais às demais instituições financeiras. Cabe destacar que esses indicadores de resultado não se mostraram significativos para o sucesso das cooperativas de crédito no estudo de Carvalho et al.(2015).

Outro quociente que ajuda a avaliar o nível de eficiência econômico-financeira das cooperativas, conforme descrito por Bressan et al. (2011a) é o de Despesas Operacionais (Figura 2). Na comparação com o total do Ativo, tanto as organizações do SICOOB quanto as do SICREDI apresentaram níveis estatisticamente mais elevados de gastos com pessoal e estrutura do que os bancos públicos e privados considerados na análise. 


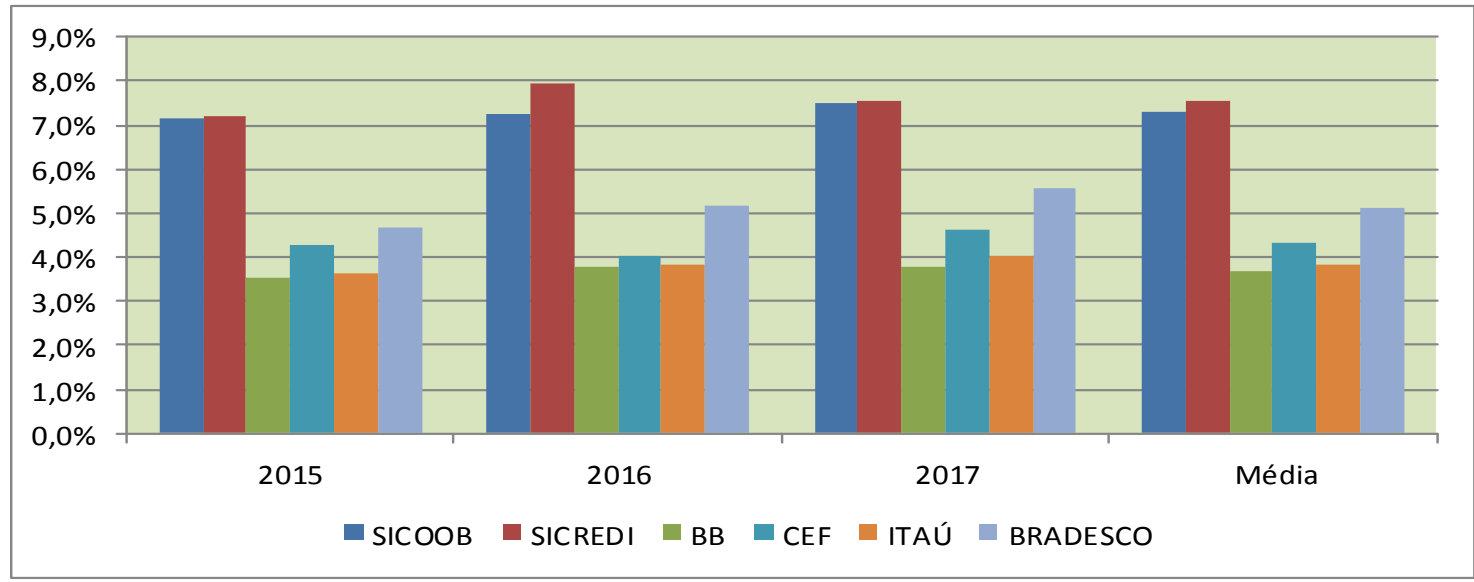

Figura 2 - Quociente de Despesas Operacionais, 2015 a 2017.

Fonte: Dados da pesquisa.

A princípio, esses números poderiam levar à conclusão de que esses sistemas são, portanto, mais ineficientes que seus competidores. Entretanto, analisando em conjunto com os valores de Rentabilidade dos Investimentos (ROA) destacados previamente, pode-se inferir que, a despeito desse maior volume de despesas, as cooperativas conseguiram níveis de retorno adequados em suas operações. Em termos práticos, portanto, pode-se dizer que, apesar dos maiores gastos operacionais, essas organizações foram mais eficientes.

Para aprofundar mais a análise, cabe destacar, nesse contexto, que as despesas operacionais envolvem os gastos com tributos e os custos relacionados à sua estrutura física, como os dispêndios de aluguel, contas de água, luz, telefone, entre outras. Contudo, o principal item desse grupo de despesas é a remuneração do seu corpo de colaboradores.

Isolando-se esse gasto específico e comparando-o com o total do Ativo das instituições analisadas, tem-se que, realmente, as cooperativas apresentam níveis de remuneração bem maiores que seus concorrentes. Enquanto a média do período, tanto para os bancos públicos quanto para os privados, fica em torno de 1,6\% de gastos com pessoal em relação aos investimentos, no SICOOB esse valor chega a $3,4 \%$ e, no SICREDI, a $3 \%$.

Esses números podem levar a duas inferências. A primeira é a de que as cooperativas, apesar de sua inserção em um mercado altamente competitivo, não se descuidaram de seus princípios sociais de valorização do indivíduo. Partindo do pressuposto de que a utilização do recurso mão-de-obra é semelhante entre as instituições do estudo, poder-se-ia dizer que os profissionais são mais valorizados nos sistemas de crédito cooperativo do que no setor bancário tradicional e que, mesmo com essa estratégia mais onerosa, essas sociedades de pessoas conseguem manter suas margens de resultado em patamares consideráveis e, até, melhores que seus principais concorrentes.

A outra conclusão plausível parte do princípio de que o nível de informatização nos bancos públicos e privados é superior, o que lhes permitiria menores gastos com pessoal. Nesse contexto, o maior peso das Despesas Operacionais em cooperativas estaria relacionado à sua defasagem tecnológica. Também sobre esse prisma, carece ressaltar que o perfil mais humanizado de atendimento é uma das características essenciais ao bom desempenho das instituições cooperativistas. Dessa forma, o maior valor relativo de gastos com pessoal poderia ser reflexo, também, de uma opção estratégica arraigada nos princípios básicos do cooperativismo.

Nesse contexto, o propósito da presente pesquisa é verificar se as cooperativas de crédito conseguem ser eficientes tanto do ponto de vista financeiro quanto social. Para esse segundo aspecto de seu desempenho, serão analisados os custos dos principais serviços bancários ofertados por essas instituições, comparando-os com os valores cobrados pelas demais instituições financeiras do País. 
A Tabela 10 explicita os custos médios (calculados a partir dos valores cobrados por esses produtos/serviços nos meses de janeiro, junho e dezembro de cada ano) de diversos produtos ofertados pelo conjunto de bancos públicos e privados nos anos de 2014 a 2017. A partir das informações mensais disponibilizadas pelo Banco Central do Brasil, foram calculados os valores anuais médios cobrados por essas organizações.

Tabela 10 - Custo Médio (R\$) de Serviços Bancários Selecionados em Bancos Públicos, Bancos Privados e Caixa Econômica Federal, 2014 a 2017.

\begin{tabular}{|c|c|c|c|c|}
\hline Serviços & 2014 & 2015 & 2016 & 2017 \\
\hline Confecção de cadastro inicial & 315,76 & 329,84 & 379,91 & 418,66 \\
\hline Cartão de débito - $2^{\underline{a}}$ via & 6,98 & 7,34 & 8,16 & 8,52 \\
\hline Fornecimento de folhas de cheque & 3,36 & 3,31 & 3,84 & 3,88 \\
\hline Exclusão do CCF & 28,59 & 30,15 & 31,53 & 32,23 \\
\hline Cheque administrativo & 20,07 & 28,16 & 36,87 & 39,60 \\
\hline Saque pessoal & 2,40 & 2,67 & 2,79 & 2,82 \\
\hline Saque no terminal & 1,83 & 2,02 & 2,13 & 1,98 \\
\hline Fornecimento de extrato & 4,05 & 4,28 & 4,44 & 4,85 \\
\hline DOC/TED pessoal & 15,00 & 15,00 & 15,00 & 15,00 \\
\hline DOC/TED agendado & 13,66 & 16,57 & 18,54 & 19,40 \\
\hline DOC/TED internet & 5,00 & 5,00 & 5,00 & 5,00 \\
\hline $\begin{array}{l}\text { Transferência entre contas da } \\
\text { própria instituição }\end{array}$ & 2,90 & 3,14 & 3,58 & 4,12 \\
\hline Cartão de crédito - 2 ${ }^{\underline{a}}$ via & 11,79 & 12,99 & 15,07 & 20,35 \\
\hline $\begin{array}{l}\text { Saques de cartão de crédito em } \\
\text { espécie }\end{array}$ & 14,27 & 15,12 & 15,30 & 15,02 \\
\hline $\begin{array}{l}\text { Pagamento por cartão de crédito } \\
\text { em espécie }\end{array}$ & 10,02 & 11,09 & 11,89 & 13,27 \\
\hline Avaliação emergencial de crédito & 17,38 & 17,86 & 19,28 & 21,52 \\
\hline Total & 473,05 & 504,54 & 573,32 & 626,20 \\
\hline
\end{tabular}

Fonte: Elaborado pelo autor a partir de dados divulgados pelo Banco Central do Brasil.

A Tabela 11, por sua vez, traz os preços médios desses mesmos serviços em cooperativas de crédito. A comparação entre os valores deixa claro o menor custo que os associados desses empreendimentos têm ao acessarem o mercado financeiro. No último ano da série, por exemplo, o custo total dos serviços elencados chegou a ser $65 \%$ menor no segmento de crédito cooperativo em relação aos seus concorrentes. Ao se considerar, apenas, as tarifas usuais após a abertura da conta, ou seja, sem a cobrança pela confecção do cadastro inicial, essa economia, em 2017, chegou a ser de $11,4 \%$. Destaca-se que, mesmo desconsiderando-se os custos de confecção de cadastro inicial, as médias dos custos de serviços bancários dos sistemas cooperativos foram estatisticamente inferiores àquelas dos bancos selecionados.

Esses cálculos foram realizados, apenas, para uma operação por tipo de serviço. Como a maior parte dos clientes faz transferências, tira extratos, saca dinheiro em caixas eletrônicos, entre outras ações, mais de uma vez por mês, o custo de se operar com cooperativas tende a ser significativamente menor, o que permite concluir que as mesmas têm contribuído para facilitar o acesso de seus usuários ao Sistema Financeiro e, portanto, vêm cumprindo seu papel social.

Resta saber se em relação às operações de crédito, os sistemas cooperativos também têm sido eficientes do ponto de vista social, ou seja, se as taxas de juros cobradas dos associados são menores do que as praticadas pelas demais instituições financeiras. Para esse tipo de análise, utilizar-se-ão os dados disponibilizados por BCB (2018a) em seu Relatório de Economia Bancária - 2017. 
Tabela 11 - Custo Médio (R\$) de Serviços Bancários Selecionados em Cooperativas de Crédito, 2014 a 2017.

\begin{tabular}{|c|c|c|c|c|}
\hline $\begin{array}{c}\text { Serviços } \\
\end{array}$ & 2014 & 2015 & 2016 & 2017 \\
\hline Confecção de cadastro inicial & 21,37 & 24,11 & 27,61 & 33,79 \\
\hline Cartão de débito - $2^{\underline{a}}$ via & 7,49 & 7,96 & 8,99 & 10,68 \\
\hline Fornecimento de folhas de cheque & 1,79 & 1,89 & 2,22 & 2,44 \\
\hline Exclusão do CCF & 36,56 & 39,50 & 43,59 & 47,15 \\
\hline Cheque administrativo & 16,23 & 16,30 & 18,96 & 20,70 \\
\hline Saque pessoal & 1,43 & 1,50 & 1,66 & 2,05 \\
\hline Saque no terminal & 1,86 & 1,80 & 1,99 & 2,25 \\
\hline Fornecimento de extrato & 1,72 & 1,92 & 2,10 & 2,35 \\
\hline DOC/TED pessoal & 12,04 & 11,87 & 11,70 & 11,83 \\
\hline DOC/TED agendado & 11,01 & 11,62 & 12,16 & 12,82 \\
\hline DOC/TED internet & 10,86 & 11,17 & 11,33 & 11,33 \\
\hline $\begin{array}{l}\text { Transferência entre contas da própria } \\
\text { instituição }\end{array}$ & 1,67 & 1,78 & 2,07 & 2,32 \\
\hline Cartão de crédito - $2^{\underline{a}}$ via & 11,34 & 13,95 & 14,83 & 18,14 \\
\hline Saques de cartão de crédito em espécie & 7,47 & 7,59 & 7,90 & 8,48 \\
\hline $\begin{array}{l}\text { Pagamento por cartão de crédito em } \\
\text { espécie }\end{array}$ & 4,54 & 4,37 & 4,43 & 7,26 \\
\hline Avaliação emergencial de crédito & 13,59 & 18,42 & 21,68 & 24,02 \\
\hline Total & 160,97 & 175,75 & 193,22 & 217,61 \\
\hline
\end{tabular}

Fonte: Elaborado pelo autor a partir de dados divulgados pelo Banco Central do Brasil.

De acordo com a Figura 3, retirada do citado relatório, desde o ano de 2006, as taxas praticadas pelos sistemas de crédito cooperativo em Empréstimos Consignados, Empréstimos sem Consignação e Financiamento de Veículos, principais operações de empréstimo/financiamento realizadas pelas cooperativas com pessoas físicas, são menores que as dos bancos (razão inferior à unidade).

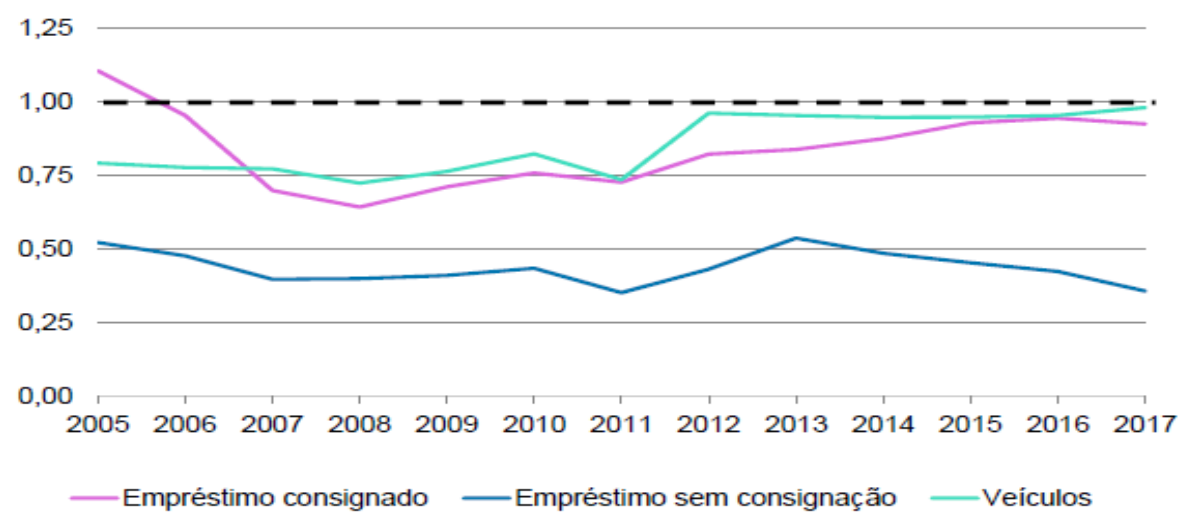

Figura 3 - Razão entre as Taxas de Juros Cobradas pelas Cooperativas e pelos Bancos - Pessoa Física. Fonte: BCB (2018a).

0 mesmo cenário, apenas um pouco mais atenuado, se verifica para o crédito direcionado às pessoas jurídicas (Figura 4). De acordo com os dados divulgados por BCB (2018a), a partir de 2014 as taxas de juros praticadas pelas cooperativas em operações de crédito destinadas a Capital de Giro, Capital de Giro Rotativo, Investimentos e Operações com Recebíveis, principais operações de empréstimo/financiamento realizadas pelas cooperativas com pessoas jurídicas, passaram a ser menores que as de seus concorrentes bancários. Talvez esse tenha sido um dos grandes motivos do seu crescimento expressivo no financiamento de empresas brasileiras nos últimos anos, conforme comentado anteriormente. 


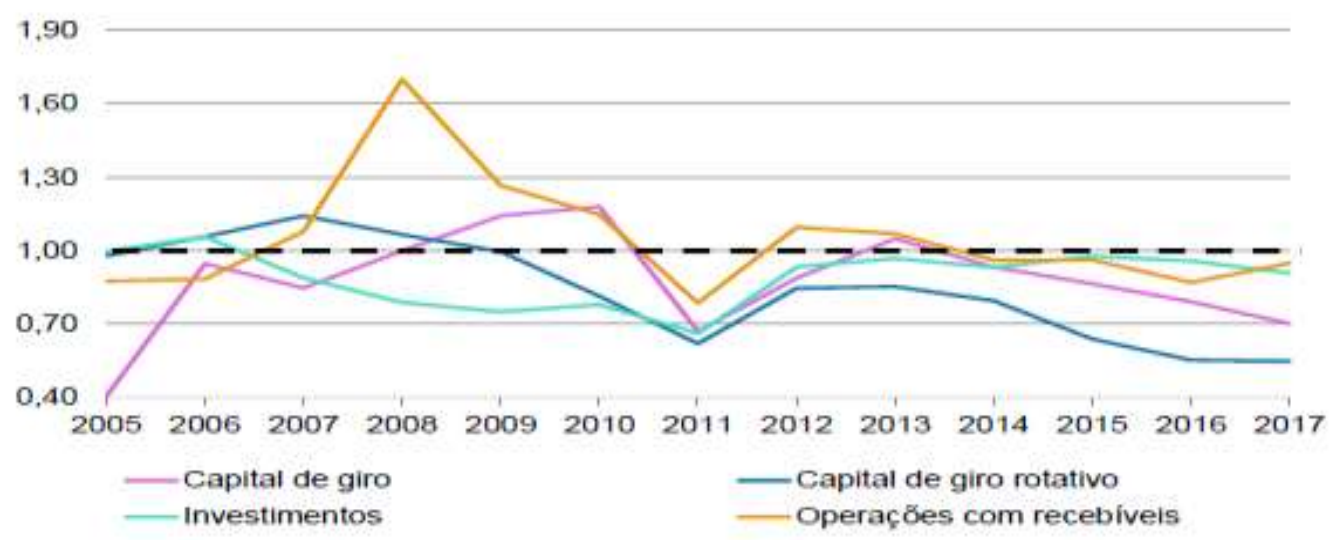

Figura 4 - Razão entre as Taxas de Juros Cobradas pelas Cooperativas e pelos Bancos - Pessoa Jurídica. Fonte: BCB (2018a).

Esse incremento, aliás, conforme destaca BCB (2018a), se deu, sobretudo, no segmento de micro e pequenas empresas. De acordo com o relatório, o crédito concedido para essas organizações pelas cooperativas financeiras cresceu de, aproximadamente, 5\% em 2015, para 10\% em 2017, enquanto os médios e grandes empreendimentos continuaram buscando mais de $98 \%$ de seus recursos externos no segmento bancário.

Além dos dados comparativos entre as taxas de juros praticadas pelas cooperativas e pelos bancos no Sistema Financeiro Nacional, o relatório de BCB (2018a) enfatiza, ainda, o papel daquelas organizações no tocante à competitividade do mercado. Embora os autores chamem a atenção para a impossibilidade de estabelecer relação causal, os dados indicam que existem correlações negativas entre o custo do crédito em instituições do segmento bancário comercial e a participação de cooperativas nas modalidades de Empréstimo Pessoal sem Consignação (pessoas físicas) e Operações com Recebíveis (pessoas jurídicas).

Esse tipo de consideração permite inferir que a partir de sua política mais social de precificação, as organizações cooperativas tendem a reduzir o afã de seus competidores na busca por maiores margens de lucratividade. Esse papel regulador torna o segmento de crédito cooperativo ainda mais relevante na busca pelo desenvolvimento econômico sustentável e inclusivo, uma vez que sua atuação permite inibir práticas mais agressivas de transferência de renda entre aqueles que dependem do sistema bancário e os conglomerados financeiros que concentram grande parte do setor no Brasil.

\section{Considerações Finais}

A principal conclusão do presente estudo se resume à afirmação de que as cooperativas de crédito, durante o período de análise, atuaram de forma eficiente tanto do ponto de vista social quanto financeiro. Os diversos indicadores calculados a partir das demonstrações consolidadas dos principais sistemas de crédito cooperativo do País e sua comparação com os valores obtidos pelos maiores bancos públicos e privados confirmaram a capacidade dos primeiros em proporcionar acesso mais amplo ao mercado bancário e, ao mesmo tempo, apresentar melhores índices de desempenho econômico.

No que tange ao oferecimento de serviços de aplicação aos seus associados, as cooperativas de crédito se destacaram pela maior representatividade dos depósitos na composição do passivo. Isso permite inferir que as mesmas tiveram papel relevante na facilitação do acesso ao mercado bancário para aqueles clientes que, muitas vezes, não interessavam às demais instituições financeiras.

Esse papel inclusivo se tornou ainda mais significativo à medida que os sistemas de crédito cooperativo aumentaram sua participação nas operações de empréstimo e financiamento destinadas 
às micro e pequenas empresas no País. Essas unidades produtivas sofreram com a falta de recursos no período recente de recessão econômica e encontraram nas cooperativas financeiras a parceria necessária para minimizar os efeitos negativos dessa situação. Como a maior parte do ativo das cooperativas foi composta por operações de crédito, tornou-se claro o papel de propulsor da atividade econômica do segmento.

0 resultado dessa estratégia se refletiu nos indicadores de rentabilidade. Os sistemas de crédito cooperativo apresentaram rendimentos operacionais superiores aos seus concorrentes no período, destacando-se nesse quesito mesmo com valores de remuneração da mão-de-obra relativamente maiores que os principais bancos públicos e privados do País. Sua eficiência operacional foi garantida por estrutura física mais enxuta e, logicamente, pela natureza do negócio, onde o lucro é limitado pelo papel social dos empreendimentos e pelos princípios cooperativistas que norteiam suas ações.

Nesse contexto de eficiência financeira, o papel social das cooperativas não foi relegado a segundo plano. A julgar pelos custos associados aos diversos serviços bancários e operações de crédito consideradas na análise, inferiores aos observados no mercado, essas organizações conseguiram obter resultados satisfatórios a partir de estratégias de negócios vinculadas aos seus princípios e valores essenciais.

Tanto os cooperados pessoas físicas quanto jurídicas usufruíram de produtos bancários em condições mais satisfatórias do que obteriam nos principais conglomerados financeiros concorrentes. Logicamente, essa vantagem está associada ao maior nível de risco assumido por esses agentes ao se tornarem sócios de cooperativas de crédito e não, simplesmente, clientes de um banco. Entretanto, a partir do maior profissionalismo que aquelas instituições financeiras alcançaram nos últimos anos, com rígidos instrumentos de controle e monitoramento, seus pontos positivos têm sido mais significativos que as desvantagens associadas à sua estrutura de governança.

Deve-se destacar que os resultados encontrados no presente trabalho, entretanto, foram obtidos a partir dos dados consolidados dos principais sistemas de crédito cooperativo do País, o que, apesar de garantir maior abrangência ao estudo, pode também se caracterizar como uma limitação da pesquisa, já que os desempenhos das cooperativas de crédito singulares não podem ser avaliados de forma individual.

Como passo seguinte no intuito de aprimoramento das conclusões sobre o desempenho das cooperativas financeiras, seria interessante a utilização de seus dados contábeis individuais (cooperativas singulares) para cálculo de indicadores. Na impossibilidade de realização de estudo censitário, nesse caso, dado o elevado número dessas instituições, a melhor alternativa poderia ser a utilização de amostra representativa do setor.

\section{Referências}

Assaf Neto, A., \& Lima, F.G. Fundamentos de Administração Financeira. São Paulo: Atlas, 2017.

Banco Central do Brasil. Relatório de Economia Bancária - 2017. Recuperado em 06 de novembro, 2018, de https://www.bcb.gov.br/pec/depep/spread/REB_2017.pdf. (2018a)Banco Central do Brasil. Panorama do sistema nacional de crédito cooperativo. Recuperado em 06 de novembro, 2018, de https://www.bcb.gov.br/pre/microFinancas/coopcar/pdf/panorama_de_cooperativas2017.pdf. (2018b).

Bialoskorski Neto, S. Economia e gestão de organizações cooperativas. São Paulo: Atlas, 2012. Bressan, V. G. F., Braga, M. J., Bressan, A. A., \& Resende Filho, M. A. Uma aplicação do sistema PEARLS às cooperativas de crédito brasileiras. Revista de Administração (FEA-USP), 46 (3), 258-274. (2011a) Bressan, V. G. F., Braga, M. J., Bressan, A. A., \& Resende Filho, M. A. Avaliação de insolvência em cooperativas de crédito: uma aplicação do sistema PEARLS. Revista de Administração Mackenzie, 12 (2), 113-144. (2011b). 
Bressan, V. G. F., Bressan, A. A., Oliveira, P. H. M. de, \& Braga, M. J. Quais indicadores contábeis financeiros do sistema PEARLS são relevantes para análise de insolvência das cooperativas centrais de crédito no Brasil? Contabilidade Vista \& Revista, 25 (1), 74-98. 2014.

Carvalho, F. L. de, Diaz, M. D. M., Bialoskorski, S., Neto \& Kalatzis, A. E. G. Saída e insucesso das cooperativas de crédito no Brasil: uma análise do risco. Revista de Contabilidade e Finanças da USP, 26 (67), 70-84. 2015.

Ferreira, M. A. M., Gonçalves, R. M. L., \& Braga, M. J. Investigação do desempenho das cooperativas de crédito de Minas Gerais por meio da Análise Envoltória de Dados (DEA). Economia Aplicada, 11 (3), 425-445. 2007.

Franke, W. Cooperativas sem capital. In: Pinho, D. B. Bases operacionais do cooperativismo. São Paulo: CNPq, 1996.

Frantz, W. Educação e cooperação: práticas que se relacionam. Sociologias, Porto alegre: UFRGS, ano 3, n. 6, jul./dez. 2001.

Frantz, W. Educação para o cooperativismo: a experiência do movimento comunitário de base de Ijuí. In: Educação Cooperativa e suas práticas. Org SCHNEIDER, J.O. Brasília: SESCOOP, 2003.

Gonçalves, R. M. L. Condicionantes do risco de liquidez em cooperativas de economia e crédito mútuo de Minas Gerais. Dissertação de Mestrado, Universidade Federal de Viçosa, Viçosa, MG, Brasil, $2005 .$. Jaccard, J., Becker, M. A., \& Wood, G. Pairwise multiple comparison procedures: A review. Psychological Bulletin, 96(3), 589. 1984.

Lilliefors, H. W. On the Kolmogorov-Smirnov test for normality with mean and variance unknown. Journal of the American statistical Association, 62(318), 399-402. 1967.

Oliveira Júnior, C. C. de. Avaliação da Eficiência Empresarial das Cooperativas. Curitiba: Organização das Cooperativas do Estado do Paraná (OCEPAR), 1996.

Peixe, J. B., \& Protil, R. M. Eficiência econômica e social das cooperativas agroindustriais paranaenses: proposta de um modelo de avaliação. Informe Gepec, 12 (2), 1-11. 2007.

Razali, N. M. \& Wah, Y. B. Power comparisons of shapiro-wilk, kolmogorov-smirnov, lilliefors and anderson-darling tests. Journal of statistical modeling and analytics, 2(1), 21-33. 2011.

Reis, B. dos S., \& Fontes, E. A. Análise da Eficiência Sócio Financeira de uma Cooperativa de Crédito de Minas Gerais. Revista de Gestão e Organizações Cooperativas, 4 (8), 33-46. 2017.

Rios, G.S.L. \& CARVALHO, D.M. Associações de agricultores familiares como estruturas de ensaio précooperativas. Economia Solidária e Ação Cooperativa (Unisinos) v.2, n.2, p.129-136, jul./dez. 2007.

Royer, J.S. The Neoclassical Theory of Cooperatives: Part I. Journal of Cooperatives. v. 28, n. 1, p. 1-19, 2014a.

Royer, J.S. The Neoclassical Theory of Cooperatives: Part II. Journal of Cooperatives. v. 28, n. 1, p. 1-19, 2014b.

Santos, C. A. dos. Cooperativa de crédito - Série empreendimentos coletivos. Brasília: SEBRAE, 2009. Silva, A. A. da. Estrutura, análise e interpretação das demonstrações contábeis. São Paulo: Atlas, 2017. Takamatsu, R. T., \& Lamounier, W. M. A importância da atualização monetária de valores para a análise das demonstrações financeiras. Contabilidade Vista \& Revista, 17 (2), 67-87. 2006. 
Trindade, M. T., Ferreira Filho, F. de A., \& Bialoskorski, S., Neto. Análise do desempenho financeiro das cooperativas de crédito brasileiras nos últimos dez anos. Anais do Encontro de Pesquisadores Latino Americanos de Cooperativismo, Ribeirão Preto, São Paulo, Brasil, 5. 2008.

Tukey, J. The problem of multiple comparisons. Unpublished preprint., Princeton University, 1953. 